\title{
Avaliação da patogenicidade de amostras de Brachyspira pilosicoli através de técnicas histopatológicas convencionais e por imuno-histoquímica ${ }^{1}$
}

\author{
Fabiana Beatriz Paulovich², Sandra Maria Borowski ${ }^{3}$, David Driemeier ${ }^{4}$, Luis \\ Eduardo Razia², Tania Allen Coutinho², Aline Beatriz Heinen Prates ${ }^{2}$, Caroline \\ Pescador $^{4}$, André Correa ${ }^{4}$ e David Emilio S.N. de Barcellos ${ }^{2}$
}

\begin{abstract}
Paulovich F.B., Borowski S.M., Driemeier D., Razia L.E., Coutinho T. A., Prates A.B.H., Pescador C., Correa A.\& Barcellos D.E.S.N. 2004. [Assessment of the pathogenicity of Brachyspira pilosicoli strains by conventional histopathological techniques and by immunohistochemistry.] Avaliação da patogenicidade de amostras de Brachyspira pilosicoli através de técnicas histopatológicas convencionais e por imuno-histoquímica. Pesquisa Veterinária Brasileira 24(3):144-148. Depto Patologia Clínica Veterinária, Faculdade de Veterinária, UFRGS, Cx. Postal 15094, Porto Alegre, RS 91540-000, Brazil. E-mail: davetpat@ vortex.ufrgs.br

The study assessed differences of pathogenicity among 19 strains of Brachyspira pilosicoli isolated from cases of diarrhea in swine in the State of Rio Grande do Sul, Brazil, using an one-day-old chick model. The chicken inoculated with live bacterial cultures were submitted to euthanasia 21 days later, and the cecum was examined histologically using hematoxylin-eosin, silver staining and immunohistochemistry with a polyclonal antibody anti-Brachyspira pilosicoli. With silver staining and immunohistochemistry, respectively, $21.59 \%$ and $70.96 \%$ of the chicken showed colonization of the cecal epithelium with B. pilosicoli. Differences in the type of colonization characterized by continuous adhesion, focal adhesion or free bacteria in the intestinal lumen were observed. Immunohistochemistry was more efficient to assess intestinal colonization, because $49.37 \%$ more colonized chicken could be detected with silver staining. With three strains, elongated figures inside the cytoplasm of epithelial cecal cells in the inoculated chicken were observed.
\end{abstract}

INDEX TERM S: Brachyspira spp, Brachyspira pilosicoli, spirochetal colitis, immunohistochemistry, pathogenesis.

RESUMO.- 0 presente trabalho avaliou diferenças de patogenicidade entre 19 cepas de Brachyspira pilosicoli isoladas de casos de diarréia em suínos no Estado do Rio Grande do Sul, usando um modelo de infecção oral de pintos de um dia. Os animais foram inoculados com uma suspensão de bactérias vivas, 21 dias após foram sacrificados e os cecos examinados por histopatologia através da hematoxilina-eosina, coloração pela prata e a imunohistoquímica usando um anticorpo policlonal anti-Brachyspira

${ }^{1}$ Recebido em 23 de janeiro de 2004.

Aceito para publicação em 28 de maio de 2004.

2Setor de Suínos, Faculdade de Veterinária da UFRGS, Av. Bento Gonçalves 9090, Porto Alegre, RS 91540-000; www.ufrgs.br/setorsuinos

${ }^{3}$ Centro de Pesquisa Veterinária Desidério Finamor, FEPAGRO, Cx. Postal 47, Eldorado do Sul, RS 92990-000.

${ }^{4}$ Depto Patologia Clínica Veterinária Faculdade de Veterinária da UFRGS. pilosicoli. Com o uso das técnicas da prata e da imuno-histoquímica, respectivamente, $21,59 \%$ e $70,96 \%$ dos pintos mostraram colonização do epitélio do ceco por B. pilosicoli. Houve diferenças no tipo de colonização, ocorrendo aderência contínua, focal ou presença de bactérias livres na luz intestinal. A imuno-histoquímica foi considerada superior para a avaliação da colonização intestinal, pois foi capaz de detectar 49,37\%de animais colonizados a mais do que com o uso da coloração pela prata. Em três cepas foram observadas figuras alongadas dentro do citoplasma das células epiteliais cecais de aves inoculadas.

TERMOS DE INDEXAÇÃO: Brachyspira spp, Brachyspira pilosicoli, colite espiroquetal, imuno-histoquímica, patogenia.

\section{INTRODUÇÃO}

Brachyspira pilosicoli éo agente da colite espiroquetal (CE), doença infecciosa dos suínos que ocorre principalmente nas fases de 
crescimento e terminação. A patogenia da infecção se relaciona principalmente com a aderência da bactéria ao epitélio do intestino grosso (Barcellos 2000). A colonização bacteriana maciça do epitélio interfere com a absorção intestinal e causa uma diarréia mucóide (Duhamel et al. 1996). Até o momento, é desconhecida a forma precisa dessa ligação. Os principais achados histopatológicos asso ciados com a CE foram descritos por Neef \& Lysons (1994), que observaram engrossamento da lâmina própria em cortes do ceco, associado a um incremento na profundidade das criptas, alterações inflamatórias e danos às células epiteliais.

Existem poucas técnicas disponíveis para a avaliação da patogenicidade de cepas B. pilosicoli. A inoculação experimental de suínos mostra resultados insatisfatórios, provavelmente por interferência com imunidade passiva transmitida pela porca aos leitões. Entretanto, a infecção pode ser reproduzida consistentemente usando um modelo de infecção em pintos de um dia (Dwars et al. 1992, Trott et al. 1995, Trott \& Hampson 1998). 0 objetivo desse trabalho foi o de avaliar diferenças na patogenicidade de cepas dessa bactéria isoladas anteriormente de granjas no Estado do Rio Grande do Sul (Barcellos et al. 2000), usando o modelo de infecção de pinto para aval iação da colonização e lesões no ceco. Para a detecção da bactéria, foram utilizadas as técnicas de imunohistoquímica e da coloração pela prata.

\section{MATERIAL E MÉTODOS}

Foram usados 88 pintos de um dia de vida, divididos em 22 lotes de 4. Em função da mistura acidental de dois grupos (inoculados com as cepas SIPV 42 e 43), o experimento final foi realizado com 20 lotes de 4 pintos e um 21음 grupo com 8 pintos. Os 4 animais de cada grupo experimental foram alojados numa mesma gaiola, isolados dos pintos dos outros grupos. Foram mantidos ainda 4 grupos de pintos como controles, com dois pintos em cada. A sala onde as gaiolas foram colocadas possuía aporte de ar filtrado e condicionamento ambiental mantendo uma temperatura média de $35^{\circ} \mathrm{C}$ e umidade média em $85 \%$ Vinte e quatro horas antes de introduzir os animais a sala e a ante-sala foram esterilizadas.

Nas primeiras 24 horas após o desafio os pintos não receberam ração ou água. A seguir, foi fornecida ração não-comercial, sem antimicrobianos. A água de bebida e a comida estiveram disponíveis "ad-libitum" durante o experimento. Os pintos foram examinados diariamente, com observação visual e análise da consistência das fezes, segundo os critérios sugeridos por Barcellos \& Sobestiansky (2003).

Foram usadas as seguintes cepas bacterianas para infectar os pintos: P 43/6/78 (ATCC 51139). É a cepa de referência da espécie, de origem inglesa e foi isolada de suínos (Taylor et al. 1980). Foi obtida através do Dr. Gerald Duhamel, Department of Veterinary Clinical Studies, Universidade de Nebraska, Lincoln, USA; SP16 (ATCC 49776). Foi isolada originalmente de seres humanos e é originária dos Estados Unidos da América (Duhamel et al. 2001). Foi obtida através do Dr. Gerald Duhamel, Lincoln, USA; SIPV 1, 8, 9, 12, 13, 14, 15, 16, 18, 19, $20,22,23,36,37,38,39,40 / 42$ e 43 . Todas foram isoladas de casos de diarréia em suínos no Brasil (Barcellos et al. 2000).

As cepas de referência apresentavam um número não discriminado de passagens e as de campo entre 4 a 7 passagens em meios artificiais de cultivo. Após ressuspensão das bactérias liofilizadas com solução salina, foram multiplicadas em agitação (300 rpm), num meio líquido pré-reduzido esterilizado (PRAS) conforme Kunkle et al., (1986) a $37^{\circ} \mathrm{C}$, por um período de 5 dias. A titulação do inóculo foi realizada por contagem bacteriana em câmara de Neubauer. Um inóculo de $0,8 \mathrm{ml}$ de uma suspensão contendo $1 \times 10^{8}$ bactérias $/ \mathrm{ml}$ foi fornecida por via oral aos 4 pintos de cada grupo no início do experimento por 3 vezes, a cada 3 horas. 0 inóculo foi fornecido por meio de seringas em cuja extremidade foi adaptada uma sonda de borracha com $5 \mathrm{~cm}$ de comprimento. Os 8 pintos dos grupos de controles foram inoculados por via oral com $0,8 \mathrm{ml}$ de solução salina estéril.

Decorridos 21 dias da inoculação, os animais foram sacrificados. Foram retirados da porção proximal, medial e distal do ceco fragmentos para a realização de cortes para anál ise histopatológica. Os fragmentos de intestino foram imediatamente imersos numa solução de formalina tamponada a 10\%por um mínimo de 1 dia e processados para exame histológico de forma convencional, conforme Prophet et al. (1992). A partir dos blocos, os tecidos eram cortados em micrótomo numa espessura de aproximadamente $5 \mu \mathrm{m}$ e montados sobre uma lâmina de microscopia. As colorações usadas foram hematoxilina-eosina e a coloração pela prata pelo método de WarthinStarry (Prophet et al. 1992).

O soro hiperimune policlonal anti-Brachyspira pilosicoli, utilizado para a técnica imuno-histoquímica foi produzido através da hiperimunização de coelhos com a cepa P43/6/78, usando uma técnica previamente descrita (Burrows \& Lemke 1981). 0 método imunohistoquímico usado foi o da Streptavidina Biotina Marcada (LSAB), conforme Gimeno et al. (2002). Como enzima utilizaram-se peroxidase e o cromógeno DAB (tetra-hidrocloreto de 3,5-diamino-benzidina) e, em alguns casos, para melhor contrastar 0 agente dos tecidos, foi utilizado a enzima fosfatase alcal ina e como cromógeno o vermelho permanente. A leitura foi feita em microscópio ótico.

\section{RESULTADOS}

\section{Achados macroscópicos}

Nenhum animal do grupo controle apresentou alterações clínicas ou lesões macroscópicas no exame anatomopatológico dos cecos. Durante as fases iniciais do experimento, os animais dos grupos inoculados apresentaram-se normais, sem alterações clínicas evidentes. As fezes, através da avaliação visual, não apresentaram variações significativas de consistência. No final do experimento, entretanto, alguns pintos apresentavam-se significativamente desidratados, mas sem diarréia.

$\mathrm{Na}$ necropsia dos animais inoculados e dos controles, foi realizado um exame detalhado dos cecos. A única lesão presente foi uma vascularização capilar evidente e presença de algumas sufusões na parte média e distal do ceco de dois pintos pertencentes aos grupos dos pintos inoculados $(2,27 \%$.

\section{Achados microscópicos}

Nenhum animal do grupo controle mostrou sinais de aderência por Brachyspira spp ao exame microscópico. Um resumo dos achados nos exames de coloração pela prata e por imunohistoquímica com relação à presença ou ausência das Brachyspira spp para os animais ino culados consta do Quadro 1.

A colonização nos animais inoculados foi detectada em 19 entre 88 (21,59\%) dos cortes examinados através da coloração pela prata caracterizada por um bordo escuro, formado pelas espiroquetas aderidas ao epitélio intestinal no bordo apical do epitélio (Fig. 1), e em 22 entre 31 (70,96\% pela técnica de imunohistoquímica. No exame histológico dos cortes de cecos em que houve colonização epitelial, foi possível observar em todos os 
Quadro 1. Aderência de B. pilosicoli em cecos de pintos experimentalmente inoculados, submetidos à coloração pela prata e imuno-histoquímica

\begin{tabular}{ccc}
\hline $\begin{array}{c}\text { Cepas } \\
\text { bacterianas }\end{array}$ & $\begin{array}{c}\text { Aderência, colora- } \\
\text { ção pela prata }\end{array}$ & $\begin{array}{c}\text { Aderência, imuno- } \\
\text { histoquímica }\end{array}$ \\
\hline P43/6/78 & $0^{\mathrm{a}} / 4^{\mathrm{b}}$ & $0^{\mathrm{a}} / 1^{\mathrm{b}}$ \\
SP16 & $0 / 4$ & $0 / 1$ \\
SIPV 1 & $1 / 4^{\mathrm{c}}$ & $2 / 2$ \\
SIPV 8 & $0 / 4^{\mathrm{d}}$ & $1 / 2^{\mathrm{c}}$ \\
SIPV 9 & $2 / 4$ & $2 / 2$ \\
SIPV 12 & $1 / 4$ & $2 / 2$ \\
SIPV 13 & $3 / 4$ & $1 / 1$ \\
SIPV 14 & $3 / 4^{\mathrm{c}}$ & $1 / 1$ \\
SIPV 15 & $3 / 4$ & $1 / 1$ \\
SIPV 16 & $2 / 4$ & $2 / 3$ \\
SIPV 18 & $1 / 4$ & $3 / 3$ \\
SIPV 19 19 & $0 / 2$ \\
SIPV 20 & $0 / 4$ & $1 / 1$ \\
SIPV 22 & $0 / 4$ & $2 / 2$ \\
SIPV 23 & $1 / 4$ & $1 / 1$ \\
SIPV 36 & $0 / 4$ & $0 / 1$ \\
SIPV 37 & $0 / 4$ & $1 / 1$ \\
SIPV 38 & $2 / 4$ & $0 / 1$ \\
SIPV 39 & $0 / 4$ & $1 / 1$ \\
SIPV 40/42 & $0 / 4$ & $1 / 1$ \\
SIPV 43 & $0 / 8$ & $0 / 1^{\mathrm{c}}$ \\
Total & $0 / 4$ & $22 / 31(70,96 \%$
\end{tabular}

a Número de pintos cujas lâminas mostraram aderência positiva.

b Número total de pintos analisados no grupo.

'Resultado negativo para aderência, mas presença de Brachyspira spp na luz intestinal de 1 pinto.

dResultado negativo para aderência, mas presença de Brachyspira spp na luz intestinal de 2 pintos.

casos uma marcada hipertrofia e hiperplasia das células epiteliais. 0 número de células inflamatórias na mucosa, principalmente polimorfonucleares e macrófagos presentes nas lâminas, foi: cepas SIPV 8,9,12,14,16,18,20,22,23,39 e 40/42: fraco; cepas SIPV 13,15 e 37: acentuado. Com relação à presença de células inflamatórias na lâmina própria, foi positiva de forma moderada no ceco dos pintos infectados com as cepas SIPV 9,13,14 e 15. As outras cepas que haviam mostrado células inflamatórias na mucosa não apresentaram reação inflamatória na lâmina própria. Em apenas uma lâmina, que correspondeu à cepa SIPV 12, observou-se descamação e necrose do epitélio intestinal. Em três casos foram visualizadas figuras alongadas paralelas entre si, no interior das células do intestino, similares às observadas na superfície intestinal em outros casos. As cepas relacionadas com presença de figuras intracelulares foram (Fig. 2) SIPV 9,36 e 43, duas das quais (SIPV 36 e 43) não mostraram colonização superficial.

Com relação ao tipo de colonização, entre 41 pintos cujas lâminas mostraram aderência; 15 apresentavam aderência focal, 16 aderência contínua e 7 , simultaneamente aderência focal e contínua em lâminas representando segmentos intestinais coletados das diferentes partes do ceco.

Detecção da bactéria através da coloração pela prata Foram negativas com o uso dessa coloração as lâminas correspondentes às cepas de referência e de campo SIPV 8,19,

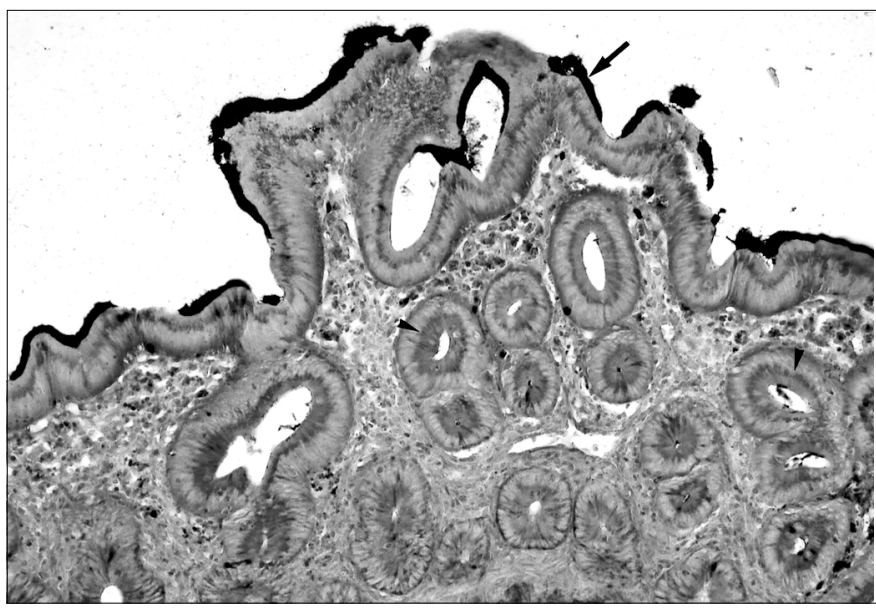

Fig. 1. Intestino grosso de frango após inoculação experimental com Brachyspira pilosicoli presença de um bordo escuro formado pela espiroquetas aderidas ao epitélio intestinal do lúmen (Seta) e linha marrom escura formada por marcação intracelular em paliçada, sugestiva de colonização intracelular pela bactéria (cabeça de seta) cepa SIPV 9. Coloração Warthin-Starry, obj. 10.

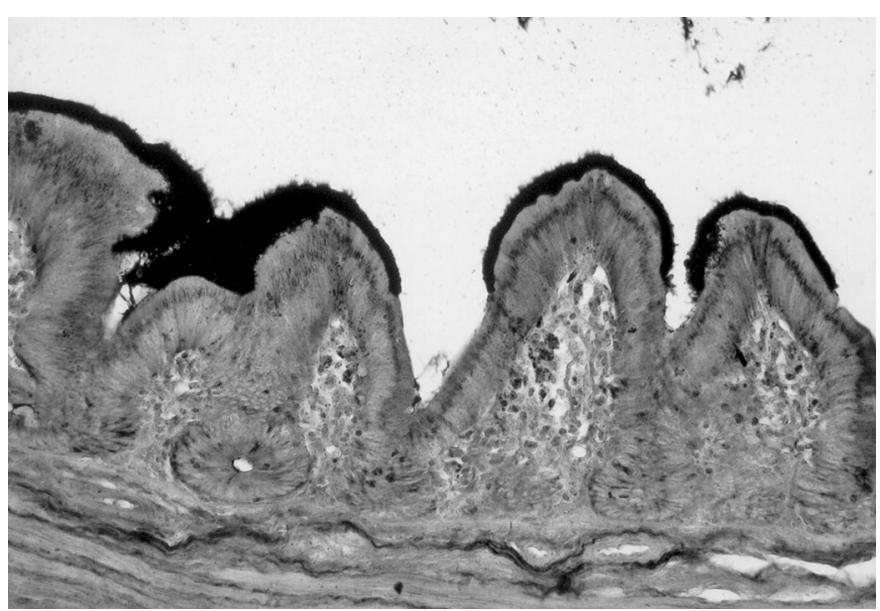

Fig. 2. Intestino grosso de frango após inoculação experimental com Brachyspira pilosicoli presença de um bordo escuro formado pela espiroquetas aderidas ao epitélio intestinal do lúmen. Coloração Warthin-Starry, obj. 20.

$20,23,36,38,39,40 / 42$ e 43 e foi observada a colonização do epitélio por espiroquetas formando uma linha no epitélio similar à borda em escova nas cepas SIPV 1, 9, 12, 13, 14, 15, 16, 18, 22 e 37. Foi visualizada uma aderência contínua das bactérias ao longo do epitélio intestinal para al gumas amostras (SIPV 13,15,22 e 37), assim como para outras houve uma aderência focal (SIPV $1,9,12,13,14,15$ e 16) e as duas situações estavam presentes na mesma lâmina em pintos das cepas SIPV 14,16 e 18. Nas lâminas correspondentes a pintos inoculados com as cepas 1,8 e 14 aparecem espiroquetas na luz intestinal e nessas foi possível comprovar a associação com outras bactérias. Em vários cortes, espiroquetas foram visualizadas dentro de glândulas intestinais (SIPV 8,9,13,14,15,16,18,20,23,37 e 43). Outro achado característico foi a presença de macrófagos na mucosa do intestino com bactérias em seu interior, produto da fagocitose. 


\section{Detecção da bactéria através da imuno-histoquímica}

Muitas alterações microscópicas foram similares às presentes na observação das lâminas coradas pela prata. A seguir, serão apresentados apenas os resultados em que as duas técnicas mostraram resultados diferentes.

Apresentaram resultado positivo para a colonização epitelial 15 entre as 21 cepas testadas $(71,4 \%$. Foram negativas as cepas de referência e as lâminas procedentes das cepas de campo SIPV 19,36,38 e 43. A colonização do epitélio intestinal esteve presente em todas as cepas restantes, de maneira focal e ao longo de toda a borda epitelial. No caso das cepas SIPV 8, além da colonização da superfície epitelial, houve a observação da presença de bactérias na luz intestinal. Na cepa 43, não foi observada colonização superficial, mas espiroquetas foram encontradas livres na luz intestinal. Algumas cepas que haviam apresentado resultado negativo através da coloração pela prata, mostraram resultado positivo ao ser usada a imuno-histoquímica (SIPV 8,20,23,39 e 40/42). Entre as 21 amostras testadas (19 de campo e 2 de referência), 6 não mostraram aderência quando analisadas através das 2 técnicas (as 2 de referência e as SIPV 19, 36,38 e 40/42).

\section{DISCUSSÃO E CONCLUSÕES}

0 estudo demonstrou superioridade da técnica de imunohistoquímica sobre a coloração pela prata, pois houve grande diferença numérica na demonstração da aderência ao epitélio intestinal dos pintos quando comparadas as duas técnicas (respectivamente $70,96 \%$ e $21,59 \%$ de positividade). Além disso, 5 cepas que apresentaram resultado negativo pela prata foram consideradas positivas para aderência com o uso da imunohistoquímica. Ao ser usada a coloração pela prata, existiu dificuldade de visualização de Brachyspira, pois ocorreu muita coloração de fundo inespecífica e a coloração muito intensa de outras bactérias. Já a imuno-histoquímica, por colorir apenas antígenos superficiais com afinidade imunogênica aos anticorpos presentes no antisoro, permitiu a visualização exclusiva de Brachyspira, aumentando a sensibilidade da detecção.

Foi observado um alto grau de colonização intestinal nos pintos inoculados, considerando-se a aderência ao epitélio intestinal. Bactérias do gênero Brachyspira têm sido isoladas muito raramente de determinadas formas de diarréia ou de casos de queda de postura em frangos, principalmente $B$. intermedia e $B$. pilosicoli. Entretanto, as bactérias não são consideradas parte da microbiota anfibiôntica intestinal de aves domésticas, e dessa forma, é provável que os pintos utilizados no presente experimento não possuíssem anticorpos contra o agente. Esse fator, associado a uma suscetibilidade natural a B. pilosicoli, fazem do modelo de infecção oral em pintos de um dia uma ferramenta de grande utilidade para o estudo da patogenicidade de diferentes cepas de B. pilosicoli (Trott et al. 1995).

Houve diferença no grau das lesões histológicas para as distintas cepas. Especificamente para as cepas SIPV 9 e 13, notou-se uma reação não observada nas outras amostras. Consistia de maciça aderência da bactéria ao epitélio cecal e das criptas. Concomitantemente, havia uma intensa resposta inflamatória na mucosa e na lâmina própria, com presença de heterófilos e macrófagos. Entretanto, mesmo com esse grau elevado de rea- ção inflamatória, não ocorreu diarréia nos animais inoculados. Para o restante das cepas, os achados histológicos estiveram restritos à capacidade de aderência da bactéria à porção apical do epitélio da mucosa, com ocasional ocorrência de uma ou outra entre as lesões histológicas que estiveram presentes na sua totalidade no caso anterior. Uma alteração comum a todos os cortes positivos foi a hiperplasia do epitélio intestinal das vilosidades e das criptas.

A amostra padrão da espécie (P43/6/78) e o isolado de origem humana (SP16) mostraram-se não-aderentes e foram incapazes de provocar reação inflamatória, quando avaliadas pelas duas técnicas. Não encontramos referências ao uso anterior dessas cepas no presente modelo experimental, o que dificulta a análise do achado. Entretanto, essas cepas são altamente laboratorizadas, ou seja, foram submetidas em diversos países a um número muito elevado de sub-cultivos. Nessas condições, as bactérias tendem a perder al guns determinantes de virulência e apresentam redução variável em sua capacidade patogênica.

Com relação às alterações macroscópicas no ceco dos pintos, houve lesões em apenas 2,3\% embora $70,96 \%$ dos casos tivessem positivos na imuno-histoquímica. Isso demonstra baixa patogenicidade das cepas de B. pilosicoli avaliadas para esses animais e alta capacidade do organismo em se associar ao epitélio intestinal, sem causar problemas clínicos. Ausência de diarréia em pintos inoculados foi já foi descrita (Duhamel 2001). Em estudos anteriores, para a classificação de cepas patogênicas ou apatogênicas para pintos foram usados dois critérios: a colonização e a ocorrência de diarréia nos animais inoculados (Trott \& Hampson 1998). No nosso caso, pela ausência de sinais clínicos, a avaliação de patogenicidade ficou restrito aos níveis de colonização. Dessa forma, poderíamos definir as cepas por nós analisadas como de alta capacidade colonizante, mas de baixa capacidade patogênica, por não serem capazes de induzir alterações patológicas que resultassem em diarréia.

Na observação das lâminas positivas, tanto na coloração pela prata como pela imuno-histoquímica, o achado microscópico mais evidente foi a aderência da bactéria à superfície do epitélio intestinal. Num número menor de lâminas, observou-se também invasão das glândulas epiteliais, conforme havia sido relatado anteriormente (Taylor \& Trott 1997, Duhamel 2001). Uma outra observação desses autores foi uma infreqüente presença de bactérias no citoplasma de macrófagos, o que foi confirmado nas nossas observações em duas lâminas (cepas SIPV 13 e 22, na coloração pela prata e em três lâminas, cepas SIPV 8, 16,18 na imuno-histoquímica).

Com relação à presença de espiroquetas livres na luz intestinal, foi detectada pela coloração pela prata em 3 cepas e em 1 cepa por imuno-histoquímica. Pode-se especular que 0 processamento histopatológico poderia ter causado a presença da bactéria na luz intestinal. Entre os fatores que poderiam explicar essa "descamação" das bactérias aderidas, poderiam ser citados artefatos de processamento das amostras.

Um achado inusitado foi a observação microscópica de figuras alongadas, em forma de paliçada, colonizando maciçamente áreas do quarto superior do epitélio celular, próximo ao centro da célula, em 3 entre as 19 cepas analisadas $(15,78 \%$. No presente estudo, não foi possível determinar se as estruturas observa- 
das eram a B. pilosicoli inoculada, um artefato de coloração ou outra bactéria intracelular. Foi achado convincentemente apenas nas lâminas coradas pela prata, não sendo observada uma coloração de intensidade similar na imuno-histoquímica. É possível que pela localização intracelular tenha havido dificuldade na reação antígeno-anticorpo.Técnicas de recuperação antigênica e de microscopia eletrônica deverão ser aplicadas posteriormente. Até recentemente, espiroquetas do gênero Brachyspira não haviam sido descritas como parasitas intracelulares em animais, apesar de que ocorra a invasão intraepitelial atingindo a lâmina própria e a fagocitose nesse local por macrófagos (Duhamel 2001). Essa situação mudou, pois mais recentemente Jansson \& Felström (2003) relataram a presença de evidências morfológicas da invasão de enterócitos de pintos por Brachyspira spp especialmente em áreas necróticas, em casos de diarréia natural, pela técnica da prata. Através da microscopia eletrônica confirmaram que os achados prévios correspondiam a organismos morfologicamente similares a Brachyspira spp. Também observaram, que a bactéria não estava envolvida por nenhuma membrana ou estrutura fagocítica, aparecendo livre no citoplasma de enterócitos necróticos ou intactos.

\section{REFERÊNCIAS}

Barcellos D.E.S.N. 2000. Infecção por Brachyspira spp. em suínos: epidemiologia e caracterização fenotípica e genotípica das espécies. Tese de Doutorado, Instituto de Microbiologia, UFRJ, Rio de Janeiro. $163 p$.

Barcellos D.E.S.N., Mathiesen M., Uzeda M., Kader I.T.A. \& Duhamel G. 2000. Prevalence of Brachyspira species isolated from diarrheic pigs in Brazil. Vet. Rec. 146:398-403.

Barcellos D.E.S.N. \& Sobestiansky J. 2003. Atlas de Doenças dos Suínos. Art 3 Editora, Goiânia. 208p.

Burrows M.R. \& Lemke R.M. 1981. Identification of Treponema hyodysenteriae by a rapid micro agglutination test. Vet. Rec. 108:187-189.
Duhamel G.E. 2001. Comparative pathology and pathogenesis of naturally acquired and experimentally induced colonic spirochetosis. Anim. Health Res. Rev. 2:3-17.

Duhamel G.E., Kinyon J.M., Mathiesen M.R. \& Walter D. 1996. Prevalence of porcine colonic spirochetosis in a multiple-site production system and microbial sensitivity patterns of Serpulina pilosicoli. In: Proceedings 39th American Association of Veterinary Laboratory Diagnosticians Meeting, Arkansas, p.45.

Dwars R.M., Davelaar F.G. \& Smith H.F. 1992. Infection of broiler chicks (Gallus domesticus) with human intestinal spirochaetes. Avian Pathol. 21:559-568.

Gimeno E.J., Belak K., Massone A.R. \& Ibargoyen G.S. 2002. Técnicas inmunohistoquímicas en patología veterinaria: aspectos teóricos y prácticos. Veterinaria Argentina, Buenos Aires, 6:332-339.

Jansson D.S. \& Felström C. 2003. Morphologic evidence of invasion of enterocytes by Brachyspira spp. in chicken with diarrhea. Proceedings $2^{\text {th }}$ International Conference on Colonic Spirochaetal Infections in Animals and Humans, Edinburgh.

Kunkle R.A., Harris D.L. \& Kinyon J.M. 1986. Autoclaved liquid medium for propagation of Treponema hyodysenteriae. J. Clin. Microbiol. 24:669-671. Neef N.A. \& Lysons R.J. 1994. Pathogenicity of porcine intestinal spirochetes in gnotobiotic pigs. Infect. Immun. 62:2395-2403.

Prophet E.B., Mills B., Arrington J.B. \& Sobin L.H. 1992. Laboratory Methods in Histotechnology. Armed Forces Institute of Pathology, American Registry of Pathology, Washington. 279p.

Taylor D.J, Simmons J.R. \& Laird H.M. 1980. Production of diarrhea in pigs feeding pure cultures of a spirochete differing from Treponema hyodysenteriae. Vet. Rec. 106:326-332.

Taylor D.J. \& Trott D. J. 1997. Porcine intestinal spirochaetosis and spirochaetal colitis, p.211-241. In: Hampson D.J., Stanton T.B. (ed.) Intestinal Spirochetes in Domestic Animals and Man. Vol. 8. CAB International, Cambridge.

Trott D.J., McLaren A.J. \& Hampson D.J. 1995. Pathogenicity of human and porcine intestinal spirochetes in day-old specific pathogen free chicks: an animal model for intestinal spirochetosis. Infec. Immun. 63:3705-3710.

Trott D.J. \& Hampson D.J. 1998. Evaluation of day-old specific pathogen free chicks as an experimental model for pathogenicity testing of intestinal spirochete species. J. Comp. Pathol. 118:365-381. 